- Drug users welcome the opportunity to access oral care and advice.

- The adoption of an integrated approach between providers of services helps

to ensure a favourable outcome.

- Personal dental services may be best placed to respond to drug users' needs.

\title{
A community based programme to improve access to dental services for drug users
}

\author{
S. Charnock ${ }^{1}$, S. Owen², V. Brookes ${ }^{3}$ and M. Williams ${ }^{4}$
}

In 1999 South Lancashire Health Authority published their Oral Health Improvement Plan in which they specifically identified drug users as a target group. In this paper the authors outline the development of a project, which aimed to improve access to dental services for this group. Essential to the relative success of the project was the inclusion of drug users and service providers at the outset. In addition perceived barriers, which exist between drug users and the profession have started to be broken down.

The effects of drug abuse on oral health have been well-documented. ${ }^{1-5}$ A detailed review of these problems, whilst not within the scope of this paper can be found in an article published by Titsas and Ferguson ${ }^{1}$ in 2002. They cite the work of a number of authors and it is useful to highlight some key points in their review.

Any practitioner who has treated drug users, especially those dependent on opioid drugs, will have observed a number of common oral problems. Neglect of oral and general health is frequently seen, together with an increased incidence of smooth surface caries. The reasons for this increased prevalence are complex. Economic factors may encourage the consumption of convenience foods with a high sugar content and opioids have been shown to directly

${ }^{\text {1*Assistant Director of Dental Services, Lancashire Teaching }}$ Hospitals NHS Trust, Chorley and South Ribble District General Hospital, Preston Road, Chorley PR7 1PP:

${ }^{2}$ Substance Misuse Service Manager, Lancashire Care Trust:

${ }^{3}$ Director of Dental Services, Lancashire Teaching Hospitals

NHS Trust; ${ }^{4}$ Senior Oral Health Promotion Officer,

Lancashire Teaching Hospitals NHS Trust

${ }^{*}$ Correspondence to: Steve Charnock

Email:Steven.Charnock@westlancspct.nhs.uk

\section{Refereed Paper}

doi: $10.1038 /$ sj.bdj.4811142

Received 24.09.02; Accepted 20.06.03

๑ British Dental Journal 2004; 196: 385-388

\section{Periodontal disease is also} commonly seen amongst drug users probably caused by their poor oral hygiene, xerostomia and the immuno-suppressive effect of opioids

generate a craving for sugary food. To compound these factors, opioid use (including methadone) can cause xerostomia. As part of their rehabilitation programme, drug users may be prescribed methadone in an attempt to manage their dependency. Sugar-free preparations have been developed in an attempt to reduce its cariogenicity which can be exacerbated by the practice of retaining the syrup in the mouth for some time. This may be done to prolong the absorption time or to regurgitate for later sale or injection. Additionally as abused drugs can reduce the pain associated with dental caries, users often present at a very late stage of the disease process.

Periodontal disease is also commonly seen amongst drug users probably caused by their poor oral hygiene, xerostomia and the immuno-suppressive effect of opioids. Patients who abuse drugs may also present the dentist with management problems associated with drug interactions, pain control and behavioural difficulties. ${ }^{6}$ They are notoriously poor attenders ${ }^{7,8}$ and when this behaviour is associated with the other problems outlined above they may find themselves stigmatised by the profession. ${ }^{9}$ Some authors have reported community based programmes to improve access to dental care amongst this group ${ }^{5,10}$ but for whatever reason there is a relative lack of information about access to care as compared to issues around the clinical presentation of such patients.

Members of the Community Drug and Alcohol Team (CDAT) in South Lancashire had highlighted concerns about access to dental care on behalf of their clients. It was unclear why drug users had problems accessing dental care, if indeed they did so. The South Lancashire Health Authority (SLHA) in their Oral Health Improvement Plan (OHImP) had also raised the issue. This document stated that the SLHA "will strive to ensure that members of the resident population who wish to receive dental care are able to access services on an equitable basis.' ${ }^{11}$ One of the key areas highlighted by 
Percentage

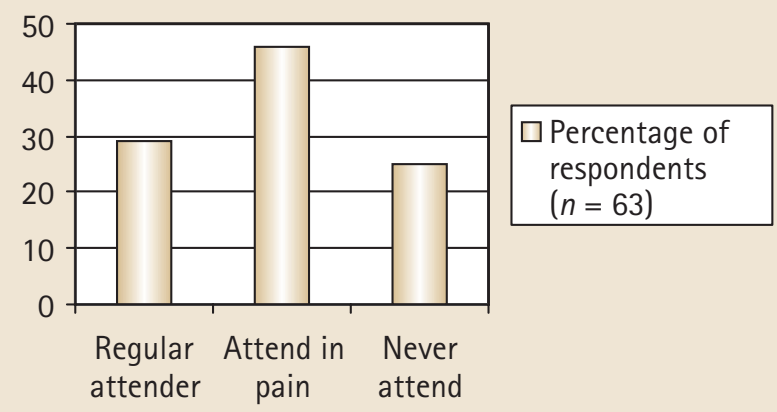

Fig. 1 Attendance pattern of drug users

the document was to develop dental services for people with drug abuse problems. However the strategy did not identify any specific targets to be achieved.

\section{NEEDS ASSESSMENT}

At the time of publication of the OHImP there was no evidence of local or expressed need. Local information was available from the Drug Misuse Database (DMD) ${ }^{12-14}$ about clients who used services provided but did not include drug users who did not access these services. It therefore could not be used to derive the prevalence of drug problems. The information available details service-users age, sex, substances used, planned prescribing, rates of injecting/ sharing and social/legal status. Our first task was to therefore try to gather some baseline information about drug users' access to dental services, their concerns about dental care and their desire to be involved with service developments.

A needs assessment was undertaken using a short questionnaire developed by the authors and the CDAT. Following a small pilot study, all clients seen by members of the CDAT during February 2000 were invited to complete the questionnaire on the understanding that anonymity was assured but without any obligation. The questionnaire attempted to identify attendance patterns, access and service development. One hundred and ninety eight clients were seen at the two centres within the locality during February 2000 with 63 (32\%) completing the questionnaire.

Forty-three (68\%) respondents reported that they were currently having problems with their teeth or mouth. Only 18 (29\%) clients considered that they were regular attenders (at least one visit each year), with 29 (46\%) reporting that they visited the dentist only when in pain. The remaining $16(25 \%)$ stated that they never visited the dentist (Fig. 1).

When asked about accessing dental care with a local dentist, 28 (44\%) indicated that they had encountered difficulties and these clients were then asked to comment on the problems that they had encountered. Fear of the dentist was the most common reason that clients reported, 16 (57\%) indicating that this was the reason they had not accessed dental care. Fourteen (50\%) felt that dentists were generally unsympathetic towards them and 9 (32\%) could not afford dental care (Fig. 2). A number of drug users (8 $(28 \%))$ were unsure as to why they found accessing dental care a problem, but then commented on their perceptions. Comments included; 'dentists are not accepting new patients', 'my registration lapsed because I kept missing appointments', 'no local NHS dentist', 'dentists don't care' and 'patients will look at me in the waiting room and know that I am a user'.

Clients were then asked if they would support a drop-in dental advice session. Fifty-six (89\%) replied that they would find this useful.

\section{RAISING AWARENESS}

These results indicated (probably not surprisingly) fairly widespread support for the idea of a drop-in and also the need to involve local general dental practitioners (GDPs) from the outset. With this in mind, approval for the project was sought and given from the local dental committee, who contacted GDPs to provide them with an outline of our proposals. In addition, all 11 general dental practices local to the CDAT were visited by a senior dental officer (SC), to discuss the project on a personal basis. Practitioners were also invited to attend a presentation by the manager of the CDAT (SO) as part of the local continuing professional development programme, the aim being to raise awareness of the work of the CDAT and to outline the effects of drug abuse on oral health. In total 38 GDPs were either visited personally or attended the local presentation.

\section{DEVELOPMENT OF THE DENTAL ADVICE SERVICE}

Members of the CDAT discussed the form that the dental advice service should take at length. At the outset it was felt that the service should operate on a 'drop-in' basis. In its most basic form it would offer advice on accessing dental care. This could theoretically be offered solely by members of the CDAT who had a list of GDPs happy to participate in any initiative and accept clients who expressed an interest in accessing dental care. However it was anticipated that the service should have a more formal arrangement. The involvement of a dentist would broaden the scope of the service, as specific referrals could be made as well as providing basic dental care on-site and introducing a dentist to the client in familiar surroundings. This would help to break down any potential barriers between client and dentist. The ideal service was considered to be the provision of a dental surgery 'on-site'. However, even if resources could allow such a development it was argued that the creation of such a specialist service would marginalize an already excluded group.

The decision was therefore taken to develop the service on a one-session/week basis staffed by a dentist and oral health promotion officer where advice and emergency treatment could be offered. Members of the CDAT suggested that to maximise the potential number of clients accessing the service, the 'drop-in' should coincide with the attendance of the medical officer who is responsible for prescribing methadone and other medication, this session being 
one of the busiest of the week. During the 'drop-in' baseline information on past dental history and attendance patterns was recorded. This enabled the dental team to follow up clients who had been referred on to dental services and ascertain any improvements to access to dental care on an individual basis.

To June 2002, fifty-two sessions had taken place with 105 users accessing the service on at least one occasion. Of these $93(88.5 \%)$ required a further referral for clinical treatment. The remainder were encouraged to register with the general dental service (GDS) and to seek regular dental care. Those users requiring treatment were questioned about their previous dental history and referred accordingly.

Users who had attended a GDP at some time during the previous 2 years (30 (32\%)) were referred back to their own dentist. A referral to the hospital dental service (HDS) was felt to be appropriate in 6 (6.5\%) cases, as four users had requested treatment under general anaesthesia and the other two required the removal of eyelet wiring which had been present for some time.

The remaining 57 (61.5\%) were referred to either the Department of Special Care Dentistry (formerly known as the community dental service or CDS) or personal dental service (PDS) dependant upon from which of the two localities they had been referred. These referrals were made as many of the users had expressed some reticence about being referred to a GDP. The reasons for this reticence appeared to reflect the perceptions highlighted in the needs assessment. Because of this it was felt that users were more likely to attend for care, if appointments were made with the service that they had requested.

Of the 93 users who were found to need clinical care, $43(46 \%)$ completed a course of treatment or are currently under care. Treatment confirmation rates were 20\% (6/30) for referrals to the GDS, 66\% (4/6) for the HDS, 38\% (10/26) for the Department of Special Care Dentistry and 74\% (23/31) for the PDS (Fig. 3).

\section{DISCUSSION}

Drug users are such a notoriously disparate and unrepresentative group that direct comparisons with other populations are difficult to justify. However because of the current lack of information about such groups comparisons may be useful to provide a stimulus for other professional colleagues who may wish to develop services for this interesting group.

The 1998 Adult Dental Health Survey ${ }^{15}$ found that $51 \%$ of dentate adults reported a problem with their oral health compared with $68 \%$ of drug users who took part in the needs assessment questionnaire. Fifty-

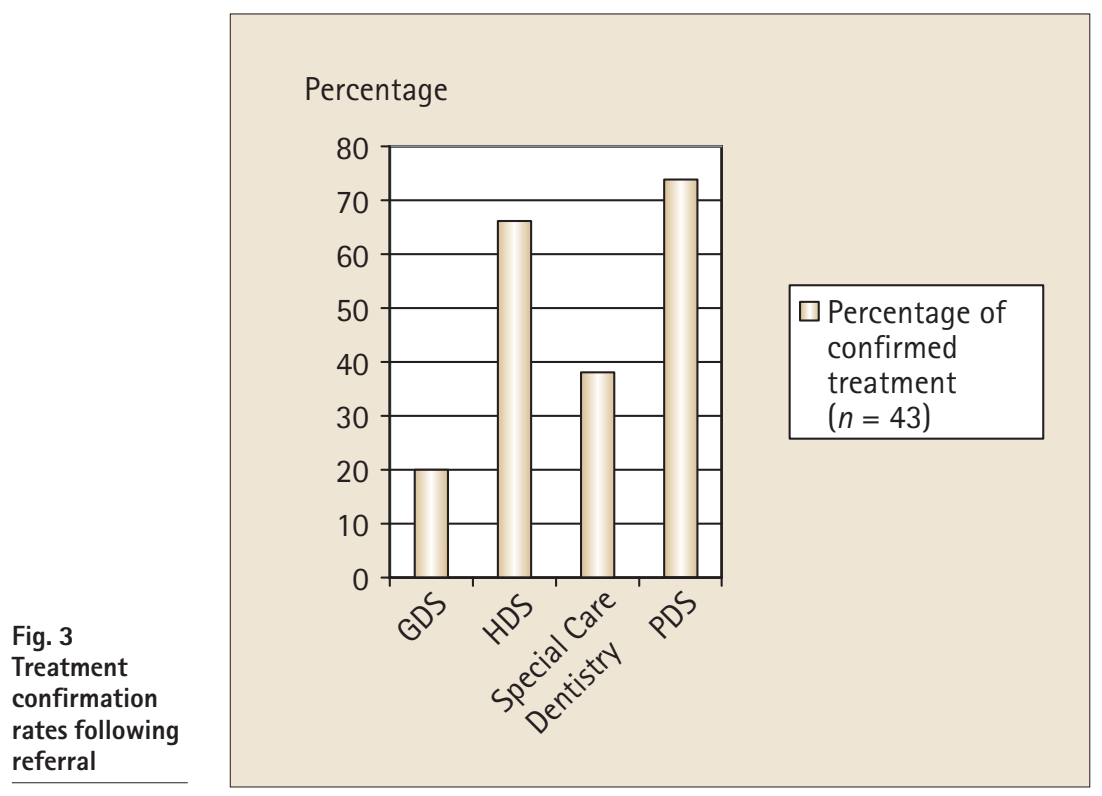

nine per cent of adults in the UK report that they are regular attenders, whilst only $29 \%$ of the users questioned placed themselves in this category. The Adult Dental Health Survey found that 30\% of those questioned only attended the dentist when in pain compared with $43 \%$ of drug users.

The finding that drug users were less likely to attend regularly and more likely to attend when in pain, is hardly surprising given that oral care is unlikely to rate highly on a drug user's list of priorities. However it is clear that they did welcome the opportunity of accessing basic care and advice in an environment which may be more responsive to their needs, as shown by the $89 \%$ of respondents who supported the development of the 'drop-in'.

It is not possible to determine the relative success of the dental advice service purely in the terms of the proportion of drug users who accessed the service. This is because the population of the group is not static as well as only being representative of the drug users known to the CDAT. Figures would suggest that about a quarter of drug users have so far made use of the service. However this equates to only two drug users being seen per session, which could be viewed, as not being very cost-effective. Costs could be reduced by altering staffing arrangements as outlined previously but this may then influence the final outcome which is to integrate drug users into dental services. This area could provide the basis for some further work by interviewing users who had accessed the service. Alternatively comparisons could be made between the relative success (as determined by confirmed treatment completion rates) of variations in staff skill mix.

Following their initial presentation, 43 $(46 \%)$ of those requiring oral care went on to complete a course of treatment or are currently under care. However the success of the PDS where 23 of the 31 drug users referred (74\%), attended for oral care, was notable. The reasons for this can only be speculated on. The authors would suggest that a number of factors could be responsible for this success. The PDS would appear to be regarded as a user-friendly service, which responds to drug users' needs. It

\section{The finding that drug users were less likely to attend regularly and more likely to attend when in pain, is hardly surprising given that oral care is unlikely to rate highly on a drug user's list of priorities}

offers a flexible appointment system where users can drop in and receive emergency treatment without a lengthy wait. They report back to members of the CDAT that they do not feel stigmatised when attending the PDS, whereas referral to the Department of Special Care Dentistry (viewed by many people as a service not providing care for 'normal' patients) may actually reinforce a feeling of exclusion.

The uptake of care within the GDS was disappointing especially as it was generally felt that GDPs had been very supportive of the project from its inception. Informal discussion with local dentists appeared to 
suggest that this was probably due to the referred users not making an initial appointment rather than the failure to complete a course of treatment once it had been commenced. This could be investigated by a follow-up questionnaire/interview with these clients to try to identify the factors behind this. Potential reasons may include apathy, the dentist/patient relationship or the perception that users had already had an examination at the drop-in and that this was sufficient.

\section{CONCLUSION}

Our aim at the onset of this study was to improve access to dental care for clients of the CDAT. This has been achieved as demonstrated by the fact that $43(46 \%)$ drug users seen at the drop-in went on to access routine dental care. This compares favourably with the 19 (29\%) drug users who reported that they attended for dental care on a regular basis at the needs assessment. However the cost of this service is high but has continued because of the direct and enlightened support of the Trusts involved. Many may consider that this is too high a price to pay for a service to such an unfashionable group.

Now that our project is established we need to consider how it should be moved forwards. Together with cost-effectiveness the other obvious area for investigation is our apparent failure to integrate drug users into the GDS.

As was mentioned in our introduction, there is a distinct lack of published information on such community-based programmes for this group.

It is hoped that this project will encourage members of the profession to look at the provision of dental care for this group and to build upon the work that has been presented in this paper.

Titsas A, Ferguson M M. Impact of opioid use on dentistry. Aust Dent J2002: 47:94-98.

2 Meechan J G. Drug Abuse and Dentistry. Dent Update 1999; 26: 182-190.

3 Milosevic A, Agrawal N, Redfearn P J, Mair L H. The occurrence of toothwear in users of Ectasy (3,4 MethyleneDioxyMethAmphetamine). Community Dent Oral Epidemiol 1999; 27: 283-287.

4 Scheutz F. Dental health in a group of drug addicts attending an addiction-clinic. Community Dent Oral Epidemiol 1984; 12: 23-28.
Scheutz F. Five-year evaluation of a dental care delivery system for drug addicts in Denmark. Community Dent Oral Epidemiol 1984; 12: 29-34.

6 Sainsbury D. Drug addiction and dental care. NZDent 1999; 95: 58-61.

7 Molendijk B, Ter Horst G, Kasbergen M, Truin G-J, Mulder J. Dental health in Dutch drug addicts. Community Dent Oral Epidemiol 1996; 24: 117-119.

8 Rosenstein D I, Van Stewart A. Dental care for patients receiving methadone. JAm Dent Assoc 1974; 89: 356-359.

9 Dawkes M, Sparkes S, Smith M, Carnwath T. Dentists' responses to drug misusers. Health Trends 1995; 27: 12-14.

10 Sheridan J, Aggleton M, Carson T. Dental health and access to dental treatment: a comparison of drug users and non-drug users attending community pharmacies. Br Dent J 2001: 191: 453-457.

11 Oral Health Improvement Plan (OHImP). South Lancashire Health, 1999.

12 Drugs Misuse Database Report 2000. Locality Report for West Lancs. Residents. Drug Misuse Research Unit. School of Epidemiology and Health Sciences. University of Manchester, April 2001.

13 Drugs Misuse Database Report 2000. Locality Report for Chorley Residents. Drug Misuse Research Unit. School of Epidemiology and Health Sciences. University of Manchester, April 2001.

14 Drugs Misuse Database Report 2000. Locality Report for South Ribble Residents. Drug Misuse Research Unit. School of Epidemiology and Health Sciences. University of Manchester, April 2001.

15 Kelly M. etal. Adult Dental Health Survey. Oral Health in the United Kingdom in 1998. London: The Stationary Office, 2000 